\title{
Biologia floral e mecanismos reprodutivos de Ocimum canum Sims (Lamiaceae)
}

\author{
Anderson Barbosa Silva ${ }^{1 *}$ \\ Marcela Fonseca Souza ${ }^{1}$ \\ Alisson Harley Brito da Silva ${ }^{2}$ \\ Obertal da Silva Almeida ${ }^{3}$ \\ Anderson Brito da Silva ${ }^{3}$ \\ Cláudio Lúcio Fernandes Amaral ${ }^{1}$ \\ ${ }^{1}$ Universidade Estadual do Sudoeste da Bahia \\ Rua Princesa Isabel, 80, CEP 45345-000, Jaguaquara - BA, Brasil \\ ${ }^{2} \mathrm{PPG}$ em Botânica Universidade Estadual de Feira de Santana - BA, Brasil \\ ${ }^{3} \mathrm{PPG}$ em Agronomia Universidade Estadual do Sudoeste da Bahia \\ *Autor para correspondência \\ andersonbioj@yahoo.com.br
}

\section{Resumo}

O gênero Ocimum (Lamiaceae) compreende plantas ricas em óleos essenciais destinados às indústrias para a produção de fármacos, perfumes, cosméticos e temperos. Foi objetivo deste trabalho estudar a biologia floral e os mecanismos reprodutivos de Ocimum canum Sims. com vistas ao melhoramento genético. Esta espécie possui inflorescências com flores brancas, perfeitas e protândricas. Os osmóforos estão localizados nas anteras e nos estigmas. A antese ocorre entre 10:30 e 11:30h. Os principais polinizadores são abelhas dos gêneros Apis e Augochloropsis. Ocimum canum apresenta sistema de cruzamento misto com predomínio de polinização cruzada sobre a auto-polinização, o que pode evidenciar a ampla flexibilidade reprodutiva desta espécie.

Unitermos: melhoramento genético, sistemas reprodutivos, polinização cruzada, autopolinização

\section{Abstract}

Floral biology and reproductive mechanisms of the Ocimum canum Sims (Lamiaceae). The Ocimum genus (Lamiaceae) presents essential oils used in the pharmaceutical, perfume, cosmetics and culinary industries. The aim of this paper was to study the floral biology and breeding mechanisms of Ocimum canum Sims. in relation to improved plant breeding. Ocimum canum has inflorescences with white, protandrous and hermaphoditic flowers. The osmophores are located at the anthers and stigma. Anthesis occurs between 10:30 and 11:30 a.m. The main floral visitors were bees of the Apis and Augochloropsis genuses. Ocimum canum presents a breeding system with a predominance of outcrossing that possibly demonstrates the wide reproductive flexibility of this species.

Key words: genetic improvement, breeding systems, outcrossing, self-crossing 


\section{Introdução}

O gênero Ocimum, pertencente à família Lamiaceae, compreende aproximadamente 30 espécies de ervas e subarbustos dispersas das regiões tropicais e subtropicais da Ásia, África, Américas Central e do Sul, sendo a África considerada o principal centro de diversidade do gênero (Paton, 1992). No Brasil são encontradas doze espécies, sendo que algumas, como $O$. basilicum e $O$. gratissimum, são cultivadas (Matos, 1998). Este gênero tem despertado a atenção de pesquisadores por apresentar espécies que são fontes de óleos essenciais (Simon et al., 1990; Morales e Simon, 1996). Entre estas espécies de grande importância encontra-se Ocimum canum Sims (manjericão-doce), que é produtora de óleos essenciais para produção de fármacos, perfumes e cosmético. Por apresentar flores e folhas de sabor suave e picante, pode ser utilizada também como condimento (Morales e Simon, 1996). Na região do Mediterrâneo, a erva é plantada nos beirais das janelas para repelir mosquitos e moscas domésticas (Duke, 1991). Estudos realizados por Montes-Belmont e Carvajal (1998) demonstraram atividade antimicrobiana, além do uso na conservação de grãos de milho.

Para obter maior produção de óleos essenciais, um dos fatores importantes é o conhecimento do sistema reprodutivo da espécie, uma vez que determina como os genes são transmitidos de uma geração para outra e como são reorganizados nos indivíduos. Devido a isto, a biologia floral e o sistema reprodutivo, em geral, são os primeiros passos a serem seguidos para o conhecimento genético de uma espécie, quando se objetiva seu melhoramento genético (Sebbenn et al., 2000).

Estudos preliminares sobre a biologia floral e sistema reprodutivo de espécies do gênero Ocimum estão representados pelos trabalhos pioneiros de Raju (1989), das espécies $O$. americanum e O. basilicum, e em estudos realizados com $O$. officinalis por Almeida et al. (2004), os quais afirmam que estas espécies são consideradas, predominantemente autógamas podendo reproduzir-se também por fecundação cruzada.

Este trabalho tem como objetivo estudar a biologia floral e os mecanismos reprodutivos de $O$. canum, visando fornecer subsídios para programas de melhora- mento genético, em face de sua grande relevância econômica e principalmente farmacológica.

\section{Material e Métodos}

Este estudo foi realizado em área experimental da Universidade Estadual do Sudoeste da Bahia (UESB) em Jequié, BA (1352'23,3'’'; 4007'39,4”'W com altitude de $216 \mathrm{~m}$ ) no período de abril de 2004 e março de 2005. O município localiza-se em uma zona limítrofe entre a Caatinga e a Zona da Mata. A região apresenta uma faixa caracterizada por clima do tipo Am (Tropical Úmido), e outra faixa com clima do tipo BSh (Koeppen, 1948), sendo a temperatura média anual do município é de $24^{\circ} \mathrm{C}$ e a precipitação pluviométrica anual varia de 500 à $750 \mathrm{~mm}$ (Almeida et al., 2004)

As plantas foram obtidas da Coleção Ativa do Banco de Germoplasma de Plantas Medicinais da UESB/Campus Jequié. Estas foram cultivadas ao ar livre em canteiros de $5 \mathrm{~m}$ (comprimento) x $1 \mathrm{~m}$ (largura) x $0,3 \mathrm{~m}$ (profundidade).

A descrição das flores e inflorescências de $O$. canum foi baseada em estudos de material vivo, e os espécimes testemunhos foram herborizados e depositados no Herbário da Universidade Estadual do Sudoeste da Bahia sob número de registro HUESB 493. Esta descrição foi feita segundo a chave analítica proposta por Bentham (1832) para identificação das espécies do gênero Ocimum.

Para o estudo da biologia floral, foi registrado o período da antese por meio de observações diárias da abertura de 50 botões florais escolhidos ao acaso, em 10 inflorescências previamente marcadas, em 10 indivíduos. Estas investigações foram conduzidas em intervalos regulares de 60 minutos ao longo de 24 horas por um período de 30 dias não consecutivos.

Para auxiliar o estudo das atividades de disponibilidade, viabilidade e germinabilidade dos grãos de pólen, bem como, receptividade dos estigmas e polinização, foi descrita a morfologia externa segundo a chave analítica proposta por Bentham (1832).

A disponibilidade polínica foi obtida por meio da quantificação de pólen retirado de anteras maceradas, 
em diferentes estádios de desenvolvimento floral, e corado com carmim acético (Almeida et al., 2004). Na contagem e análise foi utilizado microscópio (Marca Celm, modelo XS-201). Foram calculados o desvio padrão e o coeficiente de variação (C.V.) dos dados obtidos nas duas análises.

Para a viabilidade polínica, foram montadas lâminas com pólen retirado das anteras, em diferentes estádios de desenvolvimento floral, em 10 inflorescências, de 10 indivíduos, corados com carmim acético (Almeida, 1986; Dafni, 1992).

Para a determinação da germinabilidade dos grãos de pólen foram montadas lâminas com macerados de estigmas em presença de azul-de-Amã (Almeida et al., 2004), obtidos de 100 botões florais, em 10 indivíduos diferentes, e observados ao microscópio de luz. Foram considerados germinados, os grãos de pólen que apresentaram formação de tubo polínico.

Nos testes de receptividade floral foram tomados 100 estigmas, analisados por seu aspecto viscoso e umectante (Almeida, 1986). Foi utilizado também o peróxido de hidrogênio $\left(\mathrm{H}_{2} \mathrm{O}_{2}\right)$ (Kearns e Inouye, 1993) em flores da pré-antese, antese e pós-antese.

Para o estudo do sistema reprodutivo, testes de autopolinização (autogamia), polinização cruzada (alogamia), apomixia e controle foram realizados em 150 botões florais, de 20 inflorescências e de 10 indivíduos diferentes em cada um dos tratamentos. Estes tratamentos foram baseados em Dafni (1992) e Almeida et al. (2004).

Para estimar a capacidade germinativa, todas as sementes obtidas na autogamia, alogamia e apomixia foram usadas nos testes de germinação. Estas sementes foram colocadas em placas de Petri, com papel filtro, umedecidas com água destilada e acondicionadas em câmaras de germinação (incubadora: 411 D/FPD - Nova Ética ${ }^{\circledR}$ ) com temperatura de $25 \pm 1^{\circ} \mathrm{C}$ e fotoperíodo de 12 horas.

A proporção entre o número de grãos de pólen e óvulos (razão P:O) (Cruden, 1977) foi calculada em 30 flores.

Para a localização dos osmóforos foi utilizada solução de vermelho-neutro (1: 10.000) (Kearns e Inouye, 1993). As flores frescas foram mergulhadas nesta solução durante 60 minutos, lavadas com água destilada e dissecadas sob microscópio estereoscópio.

Os visitantes florais foram estudados por meio de observações in loco por um período de 30 dias não consecutivos entre os meses de outubro e dezembro de 2004, totalizando 45 horas de análises em intervalos alternados entre 07:30 e 19:30h. Os insetos foram capturados com o uso de rede entomológica ou diretamente em frascos coletores para identificação taxonômica e constatação da presença de pólen.

\section{Resultados e Discussão}

O manjericão-doce é uma planta anual, de porte herbáceo, que floresce durante todo o ano. A espécie possui inflorescências terminais, plurifloras simples do tipo indefinida, racemosa, centrípeta ou monopodial, com flores situadas em pedicelos, saindo de diversos níveis no eixo primário e atingindo diferentes alturas. As flores apresentam pré-floração do tipo valvar induplicada e são completas, perfeitas, cíclicas, hipóginas, diclamídeas e heteroclamídeas (Figura 1).

O cálice é persistente, gamossépalo, pentâmero e zigomorfo com coloração esverdeada, sendo o labelo do cálice oposto ao labelo da corola. A corola é gamopétala, pentâmera, zigomorfa e caduca, de coloração branca e, assim como o cálice, apresenta pêlos em toda sua extensão (Figura 1B e 1D).

$\mathrm{O}$ androceu é dialistêmone, oligostêmone, didínamo e epipétalo com quatro estames. As anteras são livres, dorsifixas, ditecas e extrorsas, com deiscência rimosa, sendo o filete e antera brancos. O gineceu é gamocarpelar e bicarpelar, com estigma bífido, estilete ginobásico, ambos de coloração branca. $\mathrm{O}$ ovário é súpero, tetralobado, com um disco nectarífero na base. Os frutos são tetraquênios, apresentando quatro sementes pequenas e amarronzadas (Figura 1F).

A atividade floral compreende os estádios de: pré-antese, quando os botões apresentam-se fechado e intumescido, com 4 a $6 \mathrm{~mm}$ de comprimento; antese, na qual os botões florais abrem-se assincronicamente deixando totalmente expostos o estigma e os estames; e pós-antese, quando ocorre a distensão das pétalas e sépalas. 


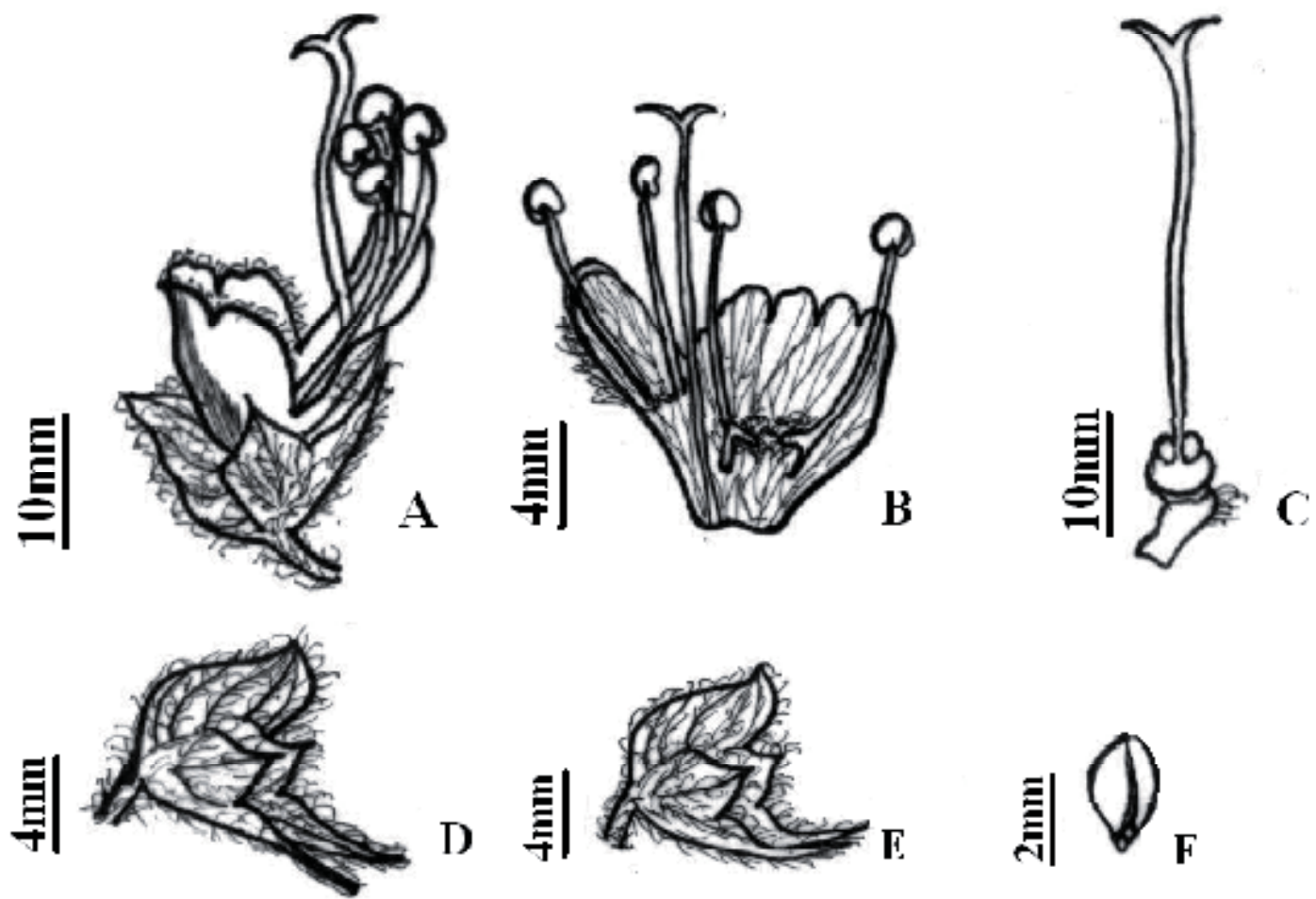

FIGURA 1: (A) Flor em antese de Ocimum canum Sims, (B) Corte longitudinal da flor, mostrando a disposição dos órgãos reprodutivos, (C) Gineceu mostrando os mesocarpos, (D) Cálice florífero, (E) Cálice frutífero e (F) Semente.

Na pré-antese, embora a flor permaneça fechada, ocorre liberação de grãos de pólen sobre o estigma, que já se encontra receptivo. Ao final deste estádio as bordas laterais do labelo do cálice dobram sobre si mesmas, formando a abertura da flor.

A antese ocorre entre 10:30 e 11:30h, com anteras já deiscentes e grãos de pólen disponíveis, os quais podem ser conduzidos por eventuais polinizadores que iniciam e intensificam suas atividades neste período. Para este estágio foi observada uma pequena taxa de germinação dos grãos de pólen de 1,70\%.

Na pós-antese detecta-se um elevado número de grãos de pólen germinados sobre o estigma, que se encontra úmido facilitando a aderência dos mesmos.

A longevidade da flor é de cerca de 24 horas. As flores não se abrem sincronicamente nas inflorescências, sendo encontradas flores em diferentes fases de desenvolvimento na mesma planta, ao longo de um dia.
A disponibilidade polínica diminui ao longo dos diferentes estádios florais (Tabela 1). A alteração na cor da corola e das anteras de O. canum, levemente amarronzadas com o passar do tempo, pode indicar a redução da disponibilidade do recurso, semelhante ao observado em Solanum lycocarpum (Oliveira-Filho e Oliveira, 1988).

TABELA 1: Disponibilidade do pólen de O. canum em três estádios florais de desenvolvimento.

\begin{tabular}{lccc}
\hline \multicolumn{1}{c}{ Estádios } & $\begin{array}{c}\text { Número } \\
\text { Total de } \\
\text { Grãos de } \\
\text { Pólen }\end{array}$ & $\begin{array}{c}\text { Média / Desvio } \\
\text { padrão }\end{array}$ & $\begin{array}{c}\text { C.V. } \\
\text { (\%) }\end{array}$ \\
\hline Pré-antese & 15223 & $761,15 \pm 625,36$ & 82,16 \\
Antese & 10371 & $691,40 \pm 187,78$ & 27,16 \\
Pós-antese & 11557 & $577,85 \pm 397,85$ & 68,85 \\
\hline
\end{tabular}

C.V. - Coeficiente de variação 
O manjericão-doce apresenta elevadas taxas de viabilidade polínica na pré-antese, antese e pós-antese (Tabela 2). Resultados semelhantes foram obtidos nos trabalhos realizados por Raju (1989), nas espécies de $O$. americanum e $O$. basilicum, e por Almeida et al. (2004) em O. officinalis.

TABELA 2: Viabilidade do pólen de $O$. canum em três estádios floral de desenvolvimento.

\begin{tabular}{lccc}
\hline $\begin{array}{c}\text { Estádios } \\
\text { Florais }\end{array}$ & $\begin{array}{c}\text { Número Total } \\
\text { de Grãos de } \\
\text { Pólen Viáveis }\end{array}$ & $\begin{array}{c}\text { Média / Desvio } \\
\text { padrão }\end{array}$ & $\begin{array}{c}\text { C.V. } \\
\text { (\%) }\end{array}$ \\
\hline Pré-antese & 14203 & $135 \pm 90,02$ & 66,68 \\
Antese & 9141 & $126 \pm 83,42$ & 66,21 \\
Pós-antese & 10516 & $106 \pm 82,67$ & 68,85 \\
\hline
\end{tabular}

C.V. - Coeficiente de variação

Segundo Flanklin et al. (1995), a viabilidade é fundamental para a análise da fertilidade do pólen, podendo auxiliar no desenvolvimento de programas de melhoramento genético. No presente estudo, foi observada uma diminuição na viabilidade dos grãos de pólen na antese, período no qual as temperaturas foram mais elevadas. De acordo com Almeida (1986), o aumento da temperatura pode proporcionar redução na taxa de viabilidade, já que a produção e viabilidade do pólen podem diminuir consideravelmente por deficiências na nutrição e por temperaturas extremas. Em algumas espécies, como Lycopersicon esculentum Mill., temperaturas elevadas na floração inibem a intumescência dos grãos de pólen. Segundo Rudich et al. (1977), a deiscência é produzida devido ao caráter higroscópico do endotécio que proporciona a força necessária para romper a zona delibitada da epiderme, as temperaturas elevadas podem afetar a estrutura do endotécio, dificultando a deiscência das anteras.

A formação do tubo polínico no estilete foi verificada nos três estádios de desenvolvimento floral, sendo que $1,20 \%$ dos grãos germinam na pré-antese, $1,70 \%$ na antese e $9,33 \%$ na pós-antese. Para Souza et al. (2002), a germinação do polén é um fator importante para o melhoramento de plantas, uma vez que o material genético presente em cada grão de polén, conseqüente das recombinações, possibilita a transmissão de genótipos diversificados.
O estigma permanece receptivo durante todos os estádios de desenvolvimento floral sendo que na pré-antese, a receptividade ocorre após a deiscência da antera. Portanto, O. canum é protândrico, confirmando os resultados obtidos por Sobti e Pushpangadan (1982) para as espécies já estudadas do gênero Ocimum, como O. basilicum e O. americanum. Almeida et al. (2004) também observaram a protandria na espécie $O$. officinalis.

Em relação ao sistema reprodutivo, o manjericãodoce apresenta maior taxa de polinização cruzada natural do que autopolinização natural (Tabela 3), o que indicando que a espécie é preferencialmente alógama. Entretanto, a possibilidade de ocorrência da autogamia, que permite a formação de sementes sem que haja necessidade de polinizadores, não pode ser descartada, já que foram obtidas sementes viáveis por este tratamento. A ocorrência de autogamia pode também ser comprovada pelo índice de Cruden (1977) encontrado neste estudo (135:1), o qual indica que $O$. canum é autógama facultativa, ou seja, esta espécie pode reproduzirse tanto por este mecanismo, quanto por fecundação cruzada.

A formação de um menor número de sementes nos frutos formados, a partir de autopolinizações manuais e espontâneas, também corrobora que a espécie seja predominantemente alógama (Siqueira Filho e Machado, 2001). As espécies do gênero Ocimum como, por exemplo, $O$. basilicum e $O$. selloi, também apresentam sistema de reprodução misto podendo se reproduzir tanto por autogamia quanto por alogamia, sendo que o sistema de reprodução misto é predominante (Nation et al., 1992).

A autogamia permite a formação de linhagens puras para caracteres de importância econômica (Paterniani, 1974), o que é interessante para a realização de cruzamentos nas gerações posteriores de Ocimum. Já a alogamia possibilita a manutenção ou aumento do vigor híbrido das espécies pela ocorrência de novas combinações de genes codificadores de caracteres de interesse agronômico (Paterniani, 1974), como por exemplo, a produção de óleos essenciais que, por serem amplamente utilizados pelas indústrias farmacêuticas, têm alto valor no mercado nacional e internacional (Nation et al., 1992). 
TABELA 3: Resultados de cruzamentos naturais e artificiais em O. canum.

\begin{tabular}{|c|c|c|c|c|c|}
\hline $\begin{array}{l}\text { Sistemas Reprodu- } \\
\text { tivos (Modalidade) }\end{array}$ & $\begin{array}{c}\text { № Total de } \\
\text { Flores Utilizadas }\end{array}$ & $\begin{array}{l}\text { № Total de } \\
\text { Mericarpos } \\
\text { Esperados } \\
\end{array}$ & $\begin{array}{c}\text { № Total de } \\
\text { Mericarpos } \\
\text { Obtidos } \\
\end{array}$ & $\begin{array}{c}\text { Sucesso } \\
\text { Reprodutivo } \\
(\%) \\
\end{array}$ & $\begin{array}{c}\text { Sementes } \\
\text { Germinadas } \\
(\%) \\
\end{array}$ \\
\hline $\begin{array}{l}\text { Autogamia (Natu- } \\
\text { ral) }\end{array}$ & 150 & 600 & 83 & 13,83 & 30 \\
\hline $\begin{array}{l}\text { Autogamia (Artifi- } \\
\text { cial) }\end{array}$ & 150 & 600 & 162 & 27,00 & 19 \\
\hline $\begin{array}{l}\text { Alogamia (Natu- } \\
\text { ral) }\end{array}$ & 150 & 600 & 400 & 66,67 & 69 \\
\hline $\begin{array}{l}\text { Alogamia (Artifi- } \\
\text { cial) }\end{array}$ & 150 & 600 & 43 & 7,17 & 25 \\
\hline Controle & 150 & 600 & 378 & 63,00 & 39 \\
\hline
\end{tabular}

Neste estudo, em todos os testes realizados, as sementes germinaram, sendo $30 \%$ delas produzidas na autogamia natural, contra $69 \%$ na alogamia natural. Dos testes artificiais, $19 \%$ das sementes na autogamia germinaram, contra $25 \%$ observado na alogamia. No grupo controle foi observado um percentual de germinação das sementes de $39 \%$.

O percentual de sementes viáveis inferior encontrado em polinizações autogâmicas quando comparado com alogâmicas, pode indicar a ocorrência de depressão endogâmica nos estágios iniciais de desenvolvimento em O. canum. Esta característica é freqüentemente observada em outras famílias, como em Orchidaceae (Stort e Martins, 1980; Stort e Galdino, 1984; Matias et al., 1996). Segundo Lande e Schemske (1985), a depressão endogâmica é usualmente encontrada em populações de plantas predominantemente alógamas, submetidas a autofecundações forçadas (Lande e Schemske, 1985).

A polinização acontece, principalmente, na pósantese com a flor já aberta, período em que foi registrada maior intensidade nas visitas dos insetos, favorecendo a alogamia, uma vez que o pólen expulso das anteras aderem o abdômen dos visitantes florais, sugerindo a contaminação do estigma com o pólen. Resultados semelhantes realizados em diferentes espécies do gênero Ocimum também foram encontrados por Khosla (1986), Krishnan (1981) e Nation et al. (1992) na espécie $O$. basilicum e $O$. amaricanum, os quais observaram que esta espécie é polinizada, principalmente, por abelhas. Entretanto, estes resultados não estão de acordo com os trabalhos de Darrah (1974) e Torrey (1989) os quais verificaram em cultivares de $O$. basilicum que as diferenças na morfologia floral podem prevenir a alogamia, dificultando o contato dos visitantes com as anteras.

As flores de $O$. canum apresentam atributos florais relacionados à síndrome floral de melitofilia (Faegri e Van Der Pijl, 1980), tais como corola pouco tubulosa, odor doce, pequena distância entre a câmara nectarífera e os verticilos férteis e antese diurna. De acordo com estudos realizados por Khosla (1986), as espécies da família Lamiaceae têm uma estrutura floral favorável à polinização por abelhas.

Os principais visitantes florais do manjericão-doce observados neste estudo são himenópteros dos gêneros Apis, Eulaema, Bombus, Augochloropsis e Megachile (Tabela 4), sendo registrado ainda dípteros e lepidópteros. A atividade destes visitantes torna-se intensa na antese e pós-antese.

TABELA 4: Visitantes florais de $O$. canum e recursos que buscavam em suas flores.

\begin{tabular}{cccc}
\hline \multirow{2}{*}{ Familia } & \multirow{2}{*}{ Espécies } & \multicolumn{2}{c}{ Recursos } \\
\cline { 3 - 4 } Apidae & Apis melifera & $\mathrm{X}$ & $\mathrm{X}$ \\
& Eulema $s p$. & $\mathrm{X}$ & \\
& Bombus $s p$. & $\mathrm{X}$ & \\
\multirow{2}{*}{ Lactidae } & Augocloropsis $s p$ & $\mathrm{X}$ & $\mathrm{X}$ \\
Megachilidae & Megachile $s p$ & $\mathrm{X}$ & \\
\hline
\end{tabular}


Os insetos que visitam as flores de $O$. canum são de hábito diurno e não apresentam a mesma regularidade nas visitas. Dentre eles, destacam-se Apis mellifera, que é considerado o polinizador mais comum do gênero Ocimum (Darrah, 1974). Apis mellifera está presente na população estudada de $O$. canum durante todo o período observado, em toda a área de ocorrência, pousando em cada visita, em várias flores e permanecendo nelas de 5 a 10 segundos. Ao movimento em busca do néctar, a abelha pressiona as pétalas para baixo balançando os estames de modo que o pólen se disperse, aderindo-se ao seu corpo. Quando a abelha deixa a flor, todas as peças florais, que tiveram suas posições alteradas, retornam à posição inicial.

O inseto, ao visitar outra flor, deixa o pólen em seu estigma. As flores, embora cleistogâmicas, recebem pólen exógeno por meio dos polinizadores. Um polinizador eficiente visita um grande número de plantas de uma mesma espécie, transportando, por sua vez, numerosos grãos de pólen em seus pêlos ramificados, o que faz de $A$. mellifera um importante vetor de pólen para $O$. canum, assim este polinizador garante elevada produção de sementes e assegura a variabilidade genética da espécie.

Abelhas dos gêneros Eulaema e Bombus pousam e permanecem de 3 a 8 segundos em cada flor de $O$. $\mathrm{Ca}$ num, enquanto Augochloropsis fica por até 30 segundos em uma única flor, da qual retira néctar e pólen. Estes polinizadores visitam também uma grande quantidade de flores de O. canum. Tal comportamento favorece a polinização cruzada, uma vez que indivíduos de diferentes populações são alcançados durante as visitas.

É válido enfatizar que, durante o experimento, foi detectada a presença de formigas por todas as partes da planta. Suas visitas iniciam-se tão logo as plantas emitam as inflorescências do eixo principal, independente da presença de flores abertas ou se abrindo. Muito raramente chegam até as flores, e quando o fazem, limitamse a percorrer as pétalas, sem causar-lhes danos.

Em um programa de melhoramento genético de O. canum, sugere-se utilizar, na formação de linhagens, a autopolinização artificial e, na produção de híbridos, a polinização cruzada natural. O maior índice de germi- nação polínica e a receptividade prolongada do estigma encontrados na pós-antese indicam este estágio como o melhor para a realização de cruzamentos artificiais intraespecífico em $O$. canum.

\section{Agradecimentos}

À Fundação de Amparo a Pesquisa do Estado da Bahia (FAPESB) pela bolsa concedida ao primeiro autor, à Universidade Estadual do Sudoeste da Bahia (UESB) e ao Grupo de Pesquisa em Biotecnologia, Genética Vegetal e Melhoramento de Plantas (PLANTGEN).

\section{Referências}

Almeida, E. C. 1986. Biologia floral e mecanismos de reprodução em Crotaria mucrota. Revista Ceres, 33 (190): 528-540.

Almeida, O. S.; Silva, A. H. B.; Silva, A. B.; Silva, A. B.; Amaral C. L. F. 2004. Estudo da biologia floral e mecanismos reprodutivos do alfavacão (Ocimum officinalis L.) visando o melhoramento genético. Acta Scientiarum, 26 (3): 343-348.

Bentham, G. 1832. Ocimum. Salvia. Labiatarum genera et species. Ridgeway L Sons, London, UK, 260pp.

Cruden, R. W. 1977. Pollen-ovule ratios: a conservative indicator of breeding systems in flowering plants. Evolution, 31: 32-46.

Dafni, A. 1992. Pollination ecology: A practical approach. Oxford University Press, New York, USA, 250pp.

Darrah, H. H. 1974. Investigations of the cultivars of basil (Ocimum). Economic Botany, 28: 63-67.

Duke, J. A. 1991. Handbook of medicinal herbs. CRC Press, Boca Raton, USA, 677pp.

Faegri, K.; Van Der Pijl, L. 1980. The principles of pollination ecology. Pergamon Press, Oxford, USA, 291pp.

Flanklin, F. H. C.; Lawrence, M. J.; Flanklin-Tong, V. E. 1995. Cell and molecular biology of self-incompatibility in flowering plants. International Review of Cytology, 158: 1-62.

Kearns, C. A.; Inouye, D. W. 1993. Techniques for pollination biologists. University Press of Colorado, Niwot, USA, 583pp.

Khosla, M. K. 1986. Inter-relationship studies of different species the genus Ocimum. Journal of Plant Anatomy Morphology, 3: $157-167$

Koeppen, W. 1948. Climatologia. Ed. Fundo de Cultura Econômica, Buenos Aires, Argentina, 478pp.

Krishnan, R. 1981. Natural outcrossing in sweet basil, Ocimum basilicum L. Industrial Perfumer, 25 (6): 74-77.

Lande, R.; Schemske, D. W. 1985. The evolution of self-fertilization and inbreeding expression in plants. I. Genetic models. Evolution, 39: 24-40.

Matias, L. Q.; Braga, P. I. S.; Freire, A. G. 1996. Biologia reprodutiva de Constantia cipoensis Porto e Brade (Orchidaceae), endêmica 
da Serra do Cipó, Minas Gerais. Revista Brasileira de Botânica, 19: $119-125$.

Matos, F. J. A. 1998. Fármacias vivas: sistema de utilização de plantas medicinais projetado para pequenas comunidades. $3^{\mathrm{a}}$ ed. EUFC, Fortaleza, Brasil, 220pp.

Montes-Belmont, R.; Carvajal, M. 1998. Control of Aspergillus flavus in maize with plant essential oils and their components. Journal of Food Protection, 61 (5): 616-619.

Morales, R. M.; Simon, J. E. 1996. New basil selections with compact inflorescence of the ornamental market. In: Janick, J. (ed.). New crops. ASHS Press, Alexandria, USA, p.543-546.

Nation, G. R.; Janick, J.; Simon, E. J. 1992. Estimation of outcrossing in basil. HortScience, 27 (11): 1221-1222.

Oliveira-Filho, A. T.; Oliveira, L. C. A. 1988. Biologia floral de uma população de Solanum lycocarpum St. Hil. (Solanaceae) em Lavras, MG. Revista Brasileira de Botânica, 11: 23-32.

Paterniani, E. 1974. Evolução dos sistemas dos vegetais. Ciência e Cultura, 26 (5): 476-481.

Paton, A. 1992. A synopsis of Ocimum L. (Labiatae) in Africa. Kew Bulletin, 47 (3): 403-435.

Raju, A. J. S. 1989. Pollination ecology of Ocimum americanum L. and $O$. basilicum L. (Lamiaceae) in India. Plant Species Biology, 4: 107-116.

Rudich, J.; Kalmar, D.; Geizenberg, C.; Harel, S. 1977. Low tensions in defined growth stages of processing tomato plants and their effects on yield and quality. Journal Horticuture Science, 52: 391-399.

Sebbenn, A. M.; Kageyama, P. Y.; Siqueira, A. C. M. F.; Zanatto, A. C. E. 2000. Taxa de cruzamento em populações de Cariniana legalis (Mart.) O. Ktze: Implicações para a conservação e o melhoramento genético. Scientia Forestalis, 58: 25-40.

Siqueira Filho, J. A.; Machado, I. C. 2001. Biologia reprodutiva de Canistrum aurantiacum E. Morren (Bromeliaceae) em remanescente da floresta atlântica, nordeste do Brasil. Acta Botanica Brasílica, 15 (3): 427-443.

Sobti, S. N.; Pushpangadan P. 1982. Studies in the genus Ocimum: cytogenetics, breeding and production of new strains of economic importance. In: Atal, C. K. \& Kapur, B. M. (eds). Cultivation and utilization of aromatic plants. Council of Scientific \& Industrial Research, Jammu-Tawi, Índia, p.457 472.

Simon, J. E.; Quinn, J.; Murray, R. G. 1990. Basil: a source of essential oils. In: Janick, J. \& Simon, J. E. (eds). Advances in new crops. Timber Press, Portland, USA, p.484-489.

Souza, M. M.; Pereira, T. N. S.; Martins, E. R. 2002. Microesporogênese e Microgametogênese associadas ao tamanho do botão floral e da antera e viabilidade polínica em Maracujazeiro-amarelo (Passiflora edulis Sims f. Flavicarpa Degener). Ciência Agrotécnica, 26 (6): 1209-1217.

Stort, M. N. S.; Galdino, G. L. 1984. Self- and cross-pollination in some species of the genus Laelia Lindl. (Orchidaceae). Revista Brasileira de Genética, 7: 671-676.

Stort, M. N. S.; Martins, P. S. 1980. Autopolinização e polinização cruzada em algumas espécies do gênero Cattleya (Orchidaceae). Ciência e Cultura, 32: 1080-1084.

Torrey, T. 1989. Breeding herbs of culinary and ornamental use. Proceedings of the Natural Herb Growing and Marketing Conference, San Jose, USA, p.38-40. 